\title{
A novel collaborative e-learning platform for medical students - ALERT STUDENT
}

\author{
Tiago Taveira-Gomes ${ }^{1,2^{*}}$, Areo Saffarzadeh ${ }^{2,3}$, Milton Severo ${ }^{1}$, M Jorge Guimarães ${ }^{2}$ \\ and Maria Amélia Ferreira ${ }^{1}$
}

\begin{abstract}
Background: The increasing complexity of medical curricula would benefit from adaptive computer supported collaborative learning systems that support study management using instructional design and learning object principles. However, to our knowledge, there are scarce reports regarding applications developed to meet this goal and encompass the complete medical curriculum. The aim of ths study was to develop and assess the usability of an adaptive computer supported collaborative learning system for medical students to manage study sessions.

Results: A study platform named ALERT STUDENT was built as a free web application. Content chunks are represented as Flashcards that hold knowledge and open ended questions. These can be created in a collaborative fashion. Multiple Flashcards can be combined into custom stacks called Notebooks that can be accessed in study Groups that belong to the user institution. The system provides a Study Mode that features text markers, text notes, timers and color-coded content prioritization based on self-assessment of open ended questions presented in a Quiz Mode. Time spent studying and Perception of knowledge are displayed for each student and peers using charts. Computer supported collaborative learning is achieved by allowing for simultaneous creation of Notebooks and self-assessment questions by many users in a pre-defined Group. Past personal performance data is retrieved when studying new Notebooks containing previously studied Flashcards. Self-report surveys showed that students highly agreed that the system was useful and were willing to use it as a reference tool.

Conclusions: The platform employs various instructional design and learning object principles in a computer supported collaborative learning platform for medical students that allows for study management. The application broadens student insight over learning results and supports informed decisions based on past learning performance. It serves as a potential educational model for the medical education setting that has gathered strong positive feedback from students at our school.

This platform provides a case study on how effective blending of instructional design and learning object principles can be brought together to manage study, and takes an important step towards bringing information management tools to support study decisions and improving learning outcomes.
\end{abstract}

Keywords: Medical education, Computer supported collaborative learning, E-learning, Information management, Memory retention, Computer-assisted instruction, Tailored learning, Student-centered learning, Spaced repetition

\footnotetext{
*Correspondence: tiago.taveira@me.com

1 Department of Medical Education and Simulation, Faculty of Medicine of the University of Porto, Porto, Portugal

${ }^{2}$ ALERT Life Sciences Computing, Vila Nova de Gaia, Portugal

Full list of author information is available at the end of the article
} 


\section{Background}

Medical education is an area of increasing complexity, considering the education goals of health professionals for the XXI century $[1,2]$. Successful medical learning requires a considerable time investment not only in the development of core and specific competencies, but also in the ability to transfer basic cognitive competencies to the clinical setting through the integration of personal experience and vast information sources [1,3].

Information management regards the ability to search, identify and integrate relevant information that can be further used for critical reasoning in clinical practice [4] and is currently one of the most compelling challenges facing medical students.

\section{Approaches to enhance learning}

In many settings, information is not effectively managed during learning. The demanding learning process frequently drives students to retain knowledge to meet course goals instead of strengthening competence development [5]. According to the Adaptive Character of Thought (ACT-R) theory "time on task" is the most important factor for developing lifetime competence [6]. As the amount of knowledge to learn increases, how well time is managed in the learning processes becomes key [6]. Cognitive load theory postulates three types of cognitive load: (a) intrinsic load is the net result of task complexity and the learner expertise; (b) extraneous load is caused by superfluous processes that do not directly contribute to learning; (c) germane load is accounted by learning processes handling intrinsic cognitive load [7]. Studies have been carried to identify design guidelines and benefits of this theory in health sciences education [6,8-13].

Spaced-repetition, a learning approach that focuses on reviewing content multiple times over optimized time intervals is one of the most effective ways to improve long-term retention [14-18]. While evidence-based principles for instructional design are abundant, they are infrequently incorporated into the educational setting in a consistent and deliberate manner [19].

\section{Learning objects}

The way in which content can be organized in order to optimize learning has also been extensively studied [4,13,20-23]. Learning objects, groupings of instructional materials structured to meet specific educational objectives [23], define a set of guidelines to make content portable, interactive and reusable, [23-27] therefore enhancing and tailoring learning [26]. They may facilitate adaptive learning by offering the chunks of content that the learner needs in order to achieve an accepted level of competence.

Other authors have identified the need to simplify the learning object authoring process to gain wider acceptance and use [28]. Additionally, the design of appropriate and effective technologies must take into account individual differences in learning, through systems that adapt based on individual progress and performance or through explicit choices made by the learner [29].

Students need tools to help retain knowledge for longer periods and easily identify materials with lesser retention rates [18]. This goal may be achieved by providing learners with personal insight on their learning effectiveness, using personal and peer progress data based on self-assessment results [26].

\section{Computer supported collaborative learning}

Currently, web applications can be a valuable tool to reach information management goals. The application of new learning technologies that has emerged as a main stream in medical education [30] is known to simplify document management, communication, student evaluation and grading [31]. However, these tools focus mainly on maximizing efficiency of administrative teaching and have little in consideration the learning tasks directed at students.

Additionally, over recent years there has been a shift in medical education where traditional instructor-centered teaching is yielding to a learner-centered model [28,32]. With the advent of social media tools that allow for collaboration and community building it is becoming more common for students to create and share materials on-line $[25,33]$. However, these materials are often not validated or reviewed by teachers $[34,35]$ and may decrease learning effectiveness as the student will need to browse, filter and validate relevant information from numerous and often conflicting information sources [36].

CSCL can add an instructor role to the learner-centered model. It can place learners in control of their own learning and transforms the role of a teacher from the sole-provider of information to a facilitator of knowledge acquisition $[28,35]$ promoting greater learning satisfaction $[17,37]$. This type of approach usually takes place in asynchronous collaboration settings where students and teachers can collaborate at different times [37-39]. Despite this potential, little evidence of effectiveness on using such tools in the health professions has been gathered $[17,40]$.

Effective information management during the learning process may be achieved through adoption of computer supported collaborative learning (CSCL) systems that provide validated content in the form of learning objects, allow student self-assessment and display tailored feedback that can be used to support study management. This data should direct further exploratory or limited learning approaches, so that knowledge acquisition may be benefited at the same time information management competences are developed. 


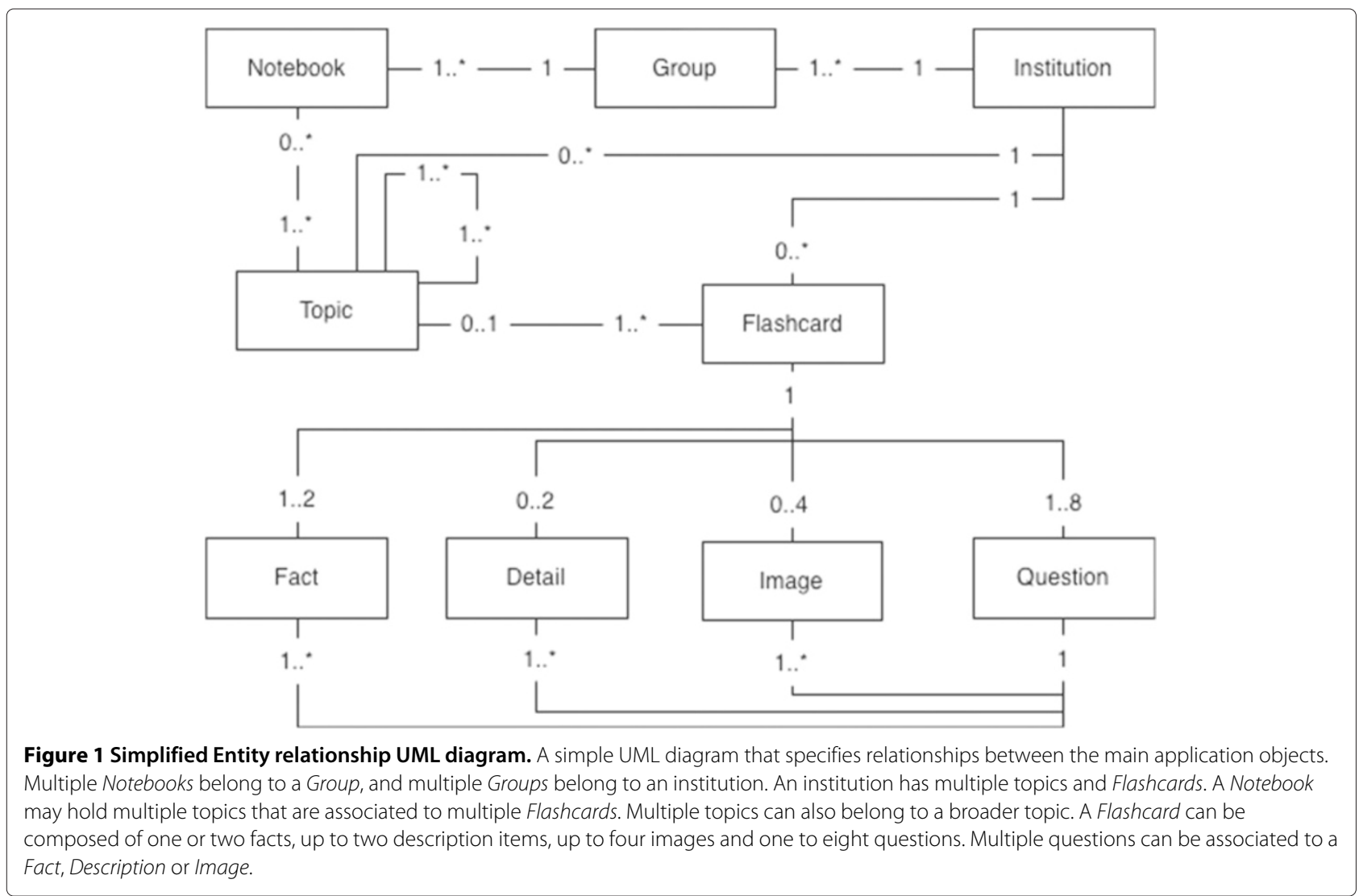

The present study aims to develop and assess the usability of an adaptive CSCL system that helps making decisions regarding personal learning process. So far, existing studies regarding such systems were built to be applied in specific medical knowledge fields [8,41-44]. To our knowledge no system has been built to be of application to medical curricula in general [45].

\section{Implementation}

\section{Technologies}

The present application was built in accordance to current web standards. The user interface was built using HyperText Markup Language (HTML), Standard Vector Graphics (SVG) and JavaScript. The application layer of the system was built using JAVA technology over the

Table 1 Variables measured by the system

\begin{tabular}{lll}
\hline Name & Meaning & Measurement and presentation \\
\hline Study session count & $\begin{array}{l}\text { The number of times a } \\
\text { Notebook has been studied }\end{array}$ & $\begin{array}{l}\text { The Study Mode provides a button that when clicked increments the study } \\
\text { session count for the Notebook. }\end{array}$ \\
\hline Time spent studying & $\begin{array}{l}\text { Timespent studying a } \\
\text { Flashcard for a study session }\end{array}$ & $\begin{array}{l}\text { Each Flashcard provides a button to mark itself as studied. Each time that } \\
\text { button is pressed, the time lapse since a previous click in any other } \\
\text { Flashcard is added to the clicked Flashcard time for the current study session. } \\
\end{array}$ \\
& $\begin{array}{l}\text { Time spent studying is presented as the cumulative time for all sessions per } \\
\text { Flashcard in a chart. It is represented as the proportion of the Flashcard time } \\
\text { to the global Notebook time on the sunburst chart. }\end{array}$ \\
\hline Perception of knowledge & $\begin{array}{l}\text { The student self perception of knowledge } \\
\text { regarding a Flashcard question. }\end{array}$ & $\begin{array}{l}\text { The student is presented an open ended question that requires recalling the } \\
\text { knowledge to answer it. After recalling the question the student can see the } \\
\text { answer and assess the quality of his recall using a 4-point likert scale. } \\
\text { Perception of knowledge is presented as the average for a given Notebook or } \\
\text { per Topic. It is represented as a percentage of the best possible } \\
\text { Perception of knowledge for a Notebook. }\end{array}$ \\
\end{tabular}


Table 2 Implementation of learning object principles

\begin{tabular}{lll}
\hline Principle & Description & Implementation \\
\hline Stand alone & $\begin{array}{l}\text { Learners can use a single learning object to } \\
\text { achieve a specified learning outcome. }\end{array}$ & $\begin{array}{l}\text { Each Flashcard encloses a small learning outcome. Combination of } \\
\text { Flashcards into Notebooks allow achievement of broader learning outcome. }\end{array}$ \\
\hline Reusability & $\begin{array}{l}\text { Learning objects can be used by diverse groups } \\
\text { of learners in a variety of educational situations. }\end{array}$ & $\begin{array}{l}\text { Flashcards created for a given Notebook can be reused to create other } \\
\text { Notebooks for different learning situations (eg.: within different Groups). }\end{array}$ \\
\hline Interactivity & $\begin{array}{l}\text { Each learning object requires an interactive } \\
\text { response from the learner. }\end{array}$ & $\begin{array}{l}\text { Flashcards and Notebooks require learners to highlight, take notes and self } \\
\text { assess their knowledge using features of the Study Mode and Quiz Mode. }\end{array}$ \\
\hline Aggregation & $\begin{array}{l}\text { Learning objects can be linked into larger collections } \\
\text { to form lessons, modules, or courses. }\end{array}$ & $\begin{array}{l}\text { Flashcards can be liked into larger collections called Notebooks. Notebooks } \\
\text { can be linked into larger collections by using Groups. }\end{array}$ \\
\hline Interoperability & $\begin{array}{l}\text { A learning object can be used with appropriate } \\
\text { "plug-ins" by multiple software applications and on }\end{array}$ & $\begin{array}{l}\text { Flashcards and Notebooks can be accessed on-line in any computer or using } \\
\text { the mobile application for the iPhone. The application interface that allows } \\
\text { communication with the iPhone also allows integration with external } \\
\end{array}$ \\
& a variety of computers and e-learning platforms. & applications. \\
\hline Accessibility & $\begin{array}{l}\text { A learning object must be tagged with standardized } \\
\text { indexing information (metadata) that allows it to be }\end{array}$ & $\begin{array}{l}\text { Flashcard are cataloged using MeSH terms and can be searched within the } \\
\text { application by using these terms. }\end{array}$ \\
& $\begin{array}{l}\text { easily found by course designers, educators, } \\
\text { learners, and evaluators. }\end{array}$ & \\
\hline
\end{tabular}

Descriptions are adapted from Ruiz et al. [23].

Play!Framework version 1.2. The database layer was built using ORACLE systems. The data model is described using a simplified UML diagram in Figure 1. A simpler version of the application was developed for the iPhone but will not be discussed in this paper.

\section{Content structure}

Content was required to be stored reusable blocks that would allow building of higher order learning blocks as well as assessing knowledge. Knowledge assessment was carried out using open ended questions. The smallest learning block was named Flashcard, and was composed of information on one side and open ended questions on the other. Each Flashcard contained up to 8 knowledge pieces named Fact, Description and Image. Questions can be associated to each of these pieces individually. Each piece would therefore serve as the answer to one or more questions. Since content re-usability was paramount, a Flashcards categorization system was implemented using Medical Subject Headings (MeSH) from the United States National Library of Medicine.

Aggregation of Flashcards in higher order structures was required to achieve meaningful learning goals. That would require creating custom aggregations of Flashcards of different MeSH topics. Topic and Flashcard order should be arranged according to the learning goal. We named these custom aggregations Notebooks.

In order for students and teachers to create and share content, Groups were created. Groups reside within institutions. Therefore, users from a given institution could access its Groups. A universal institution was created

Table 3 Implementation of instructional design principles

\begin{tabular}{|c|c|}
\hline Principle & Implementation \\
\hline Coherence principle: eliminate extraneous material & $\begin{array}{l}\text { Splitting of content into facts and description components. Ability to hide tools in Study Mode. } \\
\text { Ability to resume from where last study session was left. }\end{array}$ \\
\hline Signaling principle: highlight essential material & $\begin{array}{l}\text { Bold typeface for facts. Text marker feature. Flashcard color-coded study prioritization based } \\
\text { on learner Perception of knowledge. }\end{array}$ \\
\hline $\begin{array}{l}\text { Pre-training principle: provide pre-training in names } \\
\text { characteristics of key concepts }\end{array}$ & $\begin{array}{l}\text { Notebooks with key Flashcards can be provided before more advanced Notebooks are studied. } \\
\text { Introductory Flashcards can be added to more advanced Notebooks. }\end{array}$ \\
\hline $\begin{array}{l}\text { Segmenting principle: break lessons into } \\
\text { learner-controlled segments }\end{array}$ & Flashcard break Notebook content into learner controlled segments \\
\hline $\begin{array}{l}\text { Multimedia principle: present words and pictures } \\
\text { rather than words alone }\end{array}$ & Flashcards support both text and images \\
\hline
\end{tabular}

Principles enumerated from Mayer et al. [46]. 


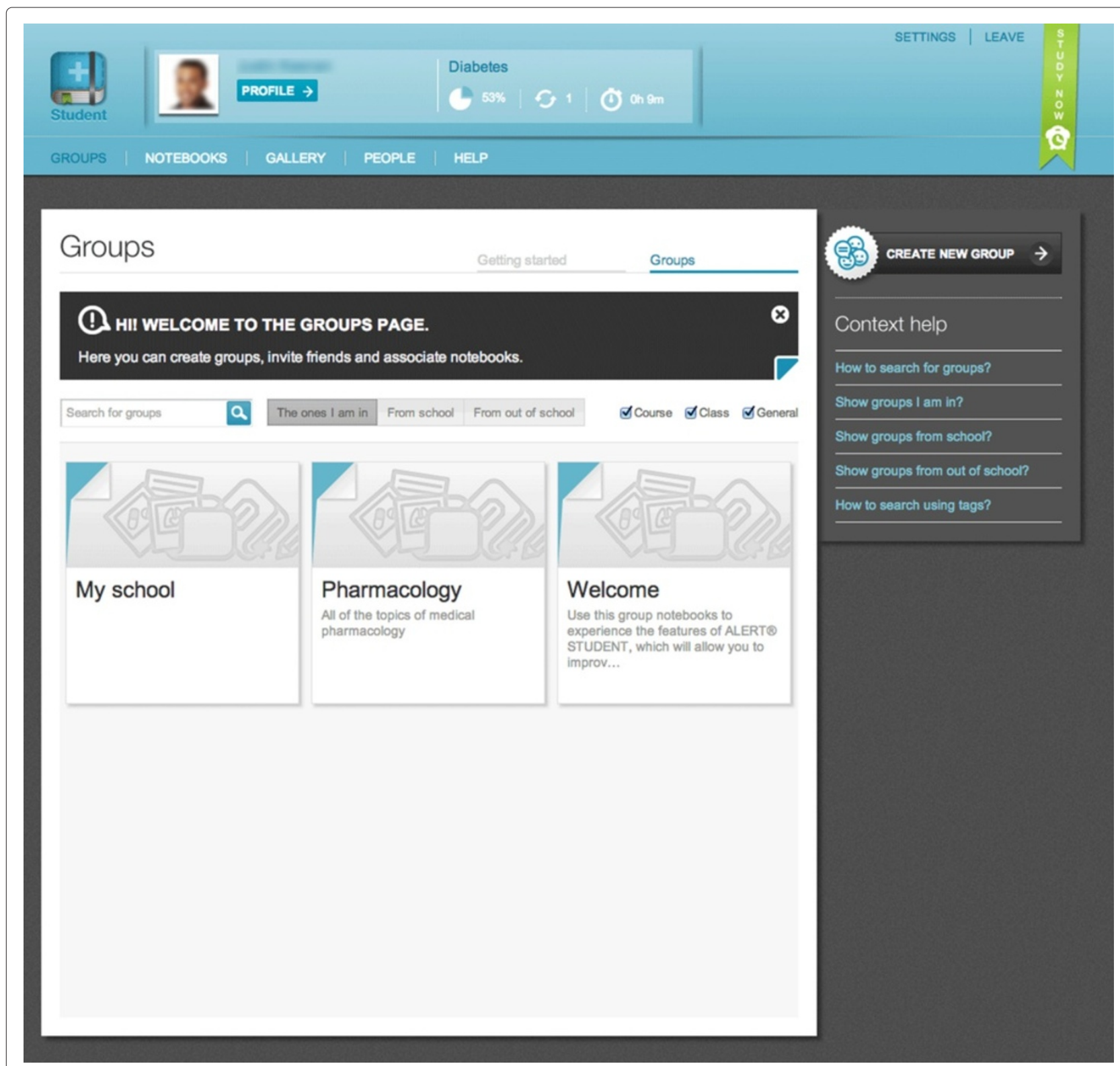

Figure 2 User Groups screen. A list of Groups for a given user is displayed.

in order to allow all users to create and share content globally.

\section{Learning tools}

User information regarding study metrics needed to be collected for study management. Time spent studying and Perception of knowledge were the two identified metrics required to meet this goal (Table 1). Perception of knowledge refers to student self perception of how well knowledge could be recalled when an openended question is presented. This data allowed computation of Flashcard study priority levels. These features were collected and presented in different sections: one devoted to study - Study Mode; another devoted to self-assessment - Quiz Mode; and a section devoted to analysis of performance metrics per Notebook Notebook Dashboard.

\section{System usability and adoption surveys}

System usability and feature usefulness of the Study Mode, Quiz Mode and Notebook Dashboard was assessed using a group of 48 students from the Faculty of Medicine of the University of Porto (FMUP) and two on-line self-report questionnaires. Students from the 4th and 5 th years of the medical course were randomly selected and contacted by email to participate in the study. 


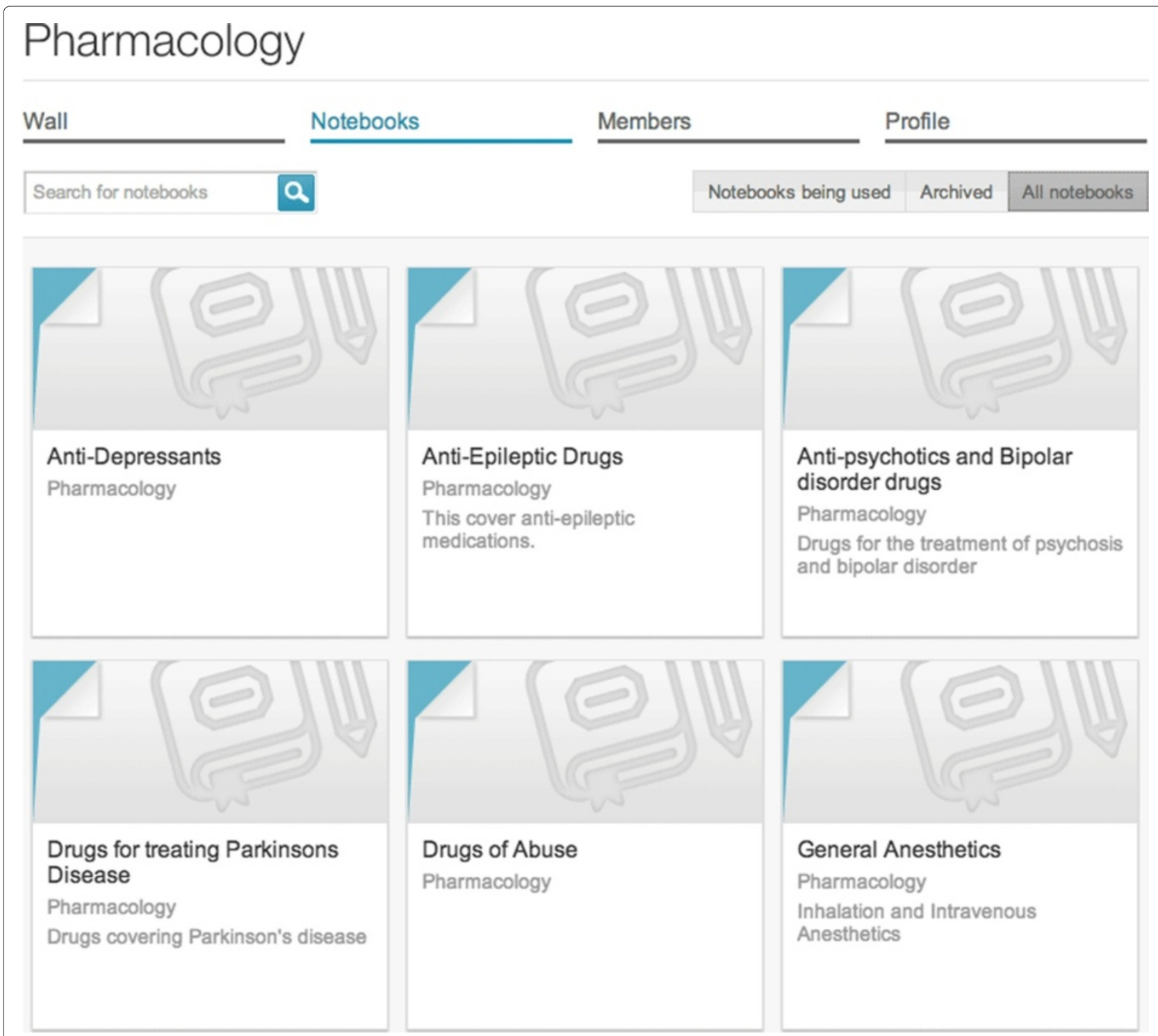

Figure 3 User Notebooks. A list of the Notebooks for a given user is displayed.

The study consisted of 2 classroom sessions (S1, S2) in consecutive weeks, with duration of 1 hour. Each student was provided a computer. The students were instructed to use the Study Mode, Quiz Mode and Notebook Dashboard to study and assess their knowledge on a Notebook about the Golgi Complex. The Notebook was created using pedagogical materials provided by the Department of Cellular and Molecular Biology of FMUP.

During S1 students had 10 minutes to register in the platform. A 2 minute explanation of how the Study Mode, Quiz Mode and Notebook Dashboard worked was given to students before they used the application. All doubts were clarified. The students then spent 20 minutes on Study Mode, 15 minutes on Quiz Mode and 5 minutes on the Notebook Dashboard. After that time the students completed an on-line survey regarding system usability and tool usefulness. Students left the room only after all students completed all tasks.

During S2 students spent equal amounts of time on the Study Mode, Quiz Mode and Notebook Dashboard. At the end of the session, the system usability and tool usefulness survey was filled again and an additional survey regarding willingness to adopt the system as a reference tool was also completed.

The 3 surveys consisted of a set of objective statements regarding personal experience. Student agreement to each of the items was assessed using a 4-point likert scale: 1 - full disagreement; 2 - partial disagreement; 3 - partial agreement; 4 - full agreement. 


\section{Topics and flashcards distribution}

\section{Amount of content Proportion of time spent}

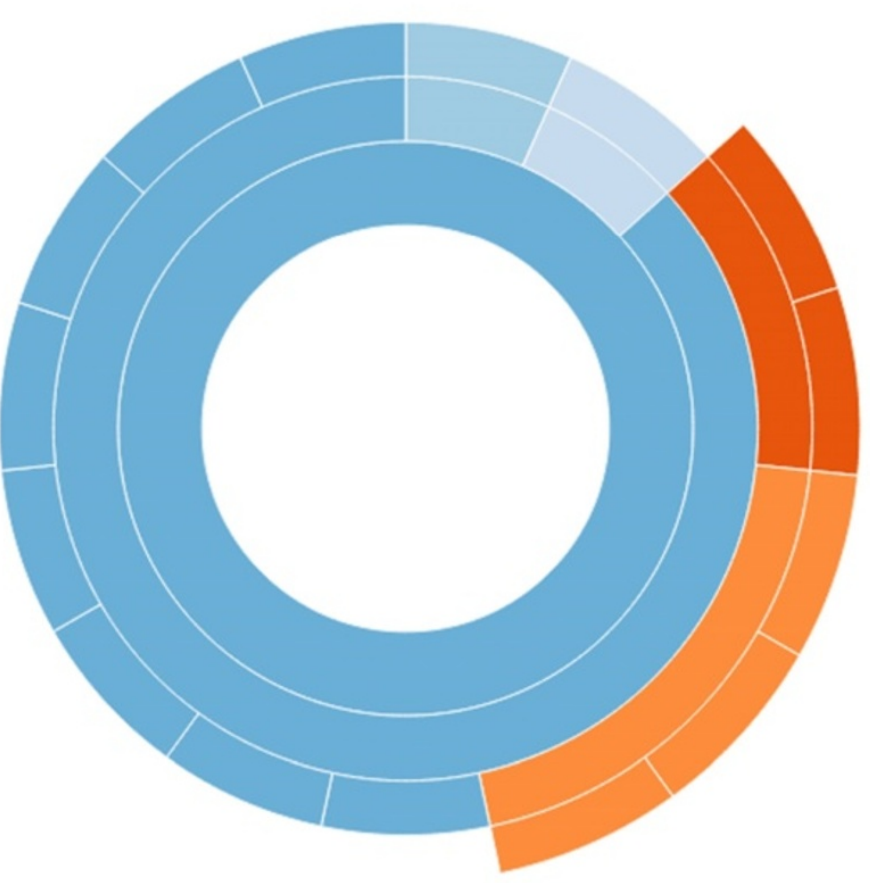

CAPTION

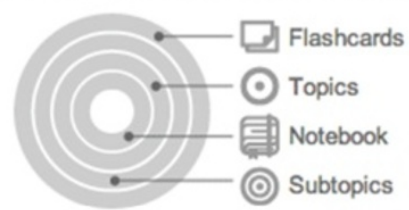

Roll the pointer over the graph to see what it refers to

\section{Knowledge by topic}

Level of personal and general knowledge on each of the notebook's topics.

\section{Me}

Colleagues

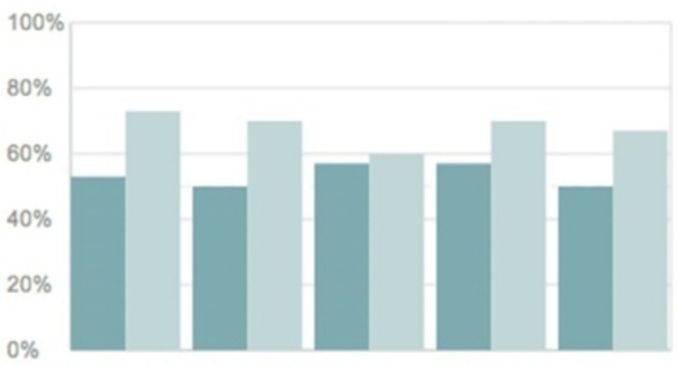

Roll the pointer over the bars to see the topic's titlo

\section{Progress}

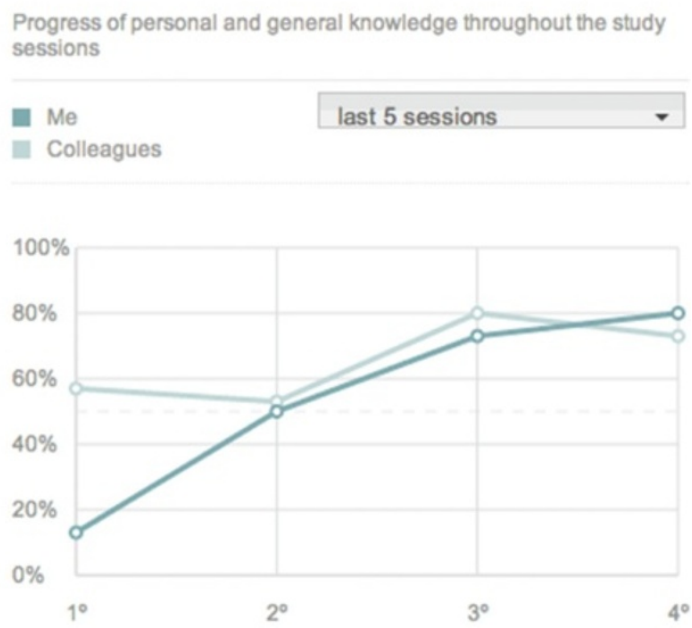

$4^{\circ}$

Figure 4 Notebook Dashboard. The sunburst chart represents the topic and Flashcard distribution. The toggle button switches the configuration between Flashcard size (given by the number of characters) and Time spent studying on a Notebook. The bar chart on the left depicts Perception of knowledge per topic, for the user and its peers. The line chart on the right is represents Perception of knowledge per quiz session for the user and its peers. 


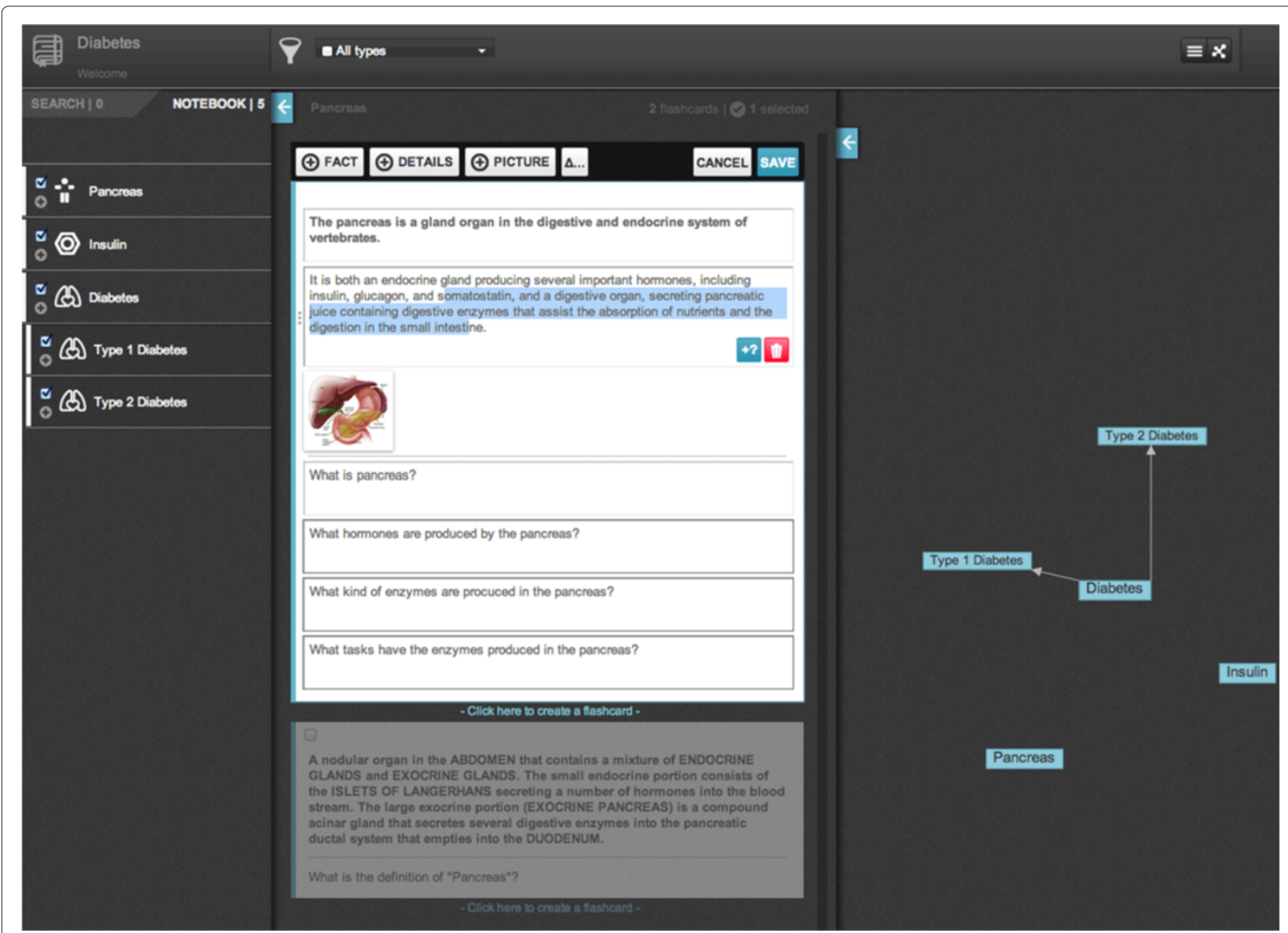

Figure 5 Notebook editor. Topics can be browsed on the left column on the search tab. Checked topics become part of the Notebook and become available on the notebook tab. The center column displays Flashcards for the selected topic. Checked Flashcards become part of the Notebook. New Flashcards can be created on any topic. On the right MeSH relationships between topics are represented using a graph that can be used to navigate topics.

Paired sample t-test was used to compare differences in the system usability and tool usefulness survey answers between the two sessions. Significance level was fixed at 0.05 .

This study was approved by the Faculty of Medicine University of Porto/São João Hospital Ethics Committee in compliance with the Helsinki Declaration.

\section{Results and discussion}

The platform was implemented as a free web application named ALERT STUDENT. Table 2 provides an outline of how learning objects principles were implemented in the system and Table 3 provides detail on how several instructional design features were implemented.

\section{Groups}

The application has a section devoted to Groups (Figure 2). This section consists of a page listing all Groups and specific Group pages. The list page allows browsing Groups using search by name, tags and filtering by belonging institution. The Group page was divided into 4 sections: (a) Group wall for posting and commenting; (b) member's page where Group administrators can manage members; (c) Notebook page that holds Notebooks and allows creation or editing; (d) Group profile section where non-members can see the Group summary.

Groups allow a closed environment approach where students can interact with a defined set of users and content for a given learning goal. This is similar to the wiki or blog scenario where administrators limit registration and editing privileges to selected users [25]. Allowing Flashcards within a Group to be available to other Groups of the same institution facilitates content sharing within the institution. This helps to reduce content redundancy, allows faster content creation and allows new Notebooks to be created using previously studied Flashcards. This may lessen intrinsic cognitive load by reducing the exploratory 


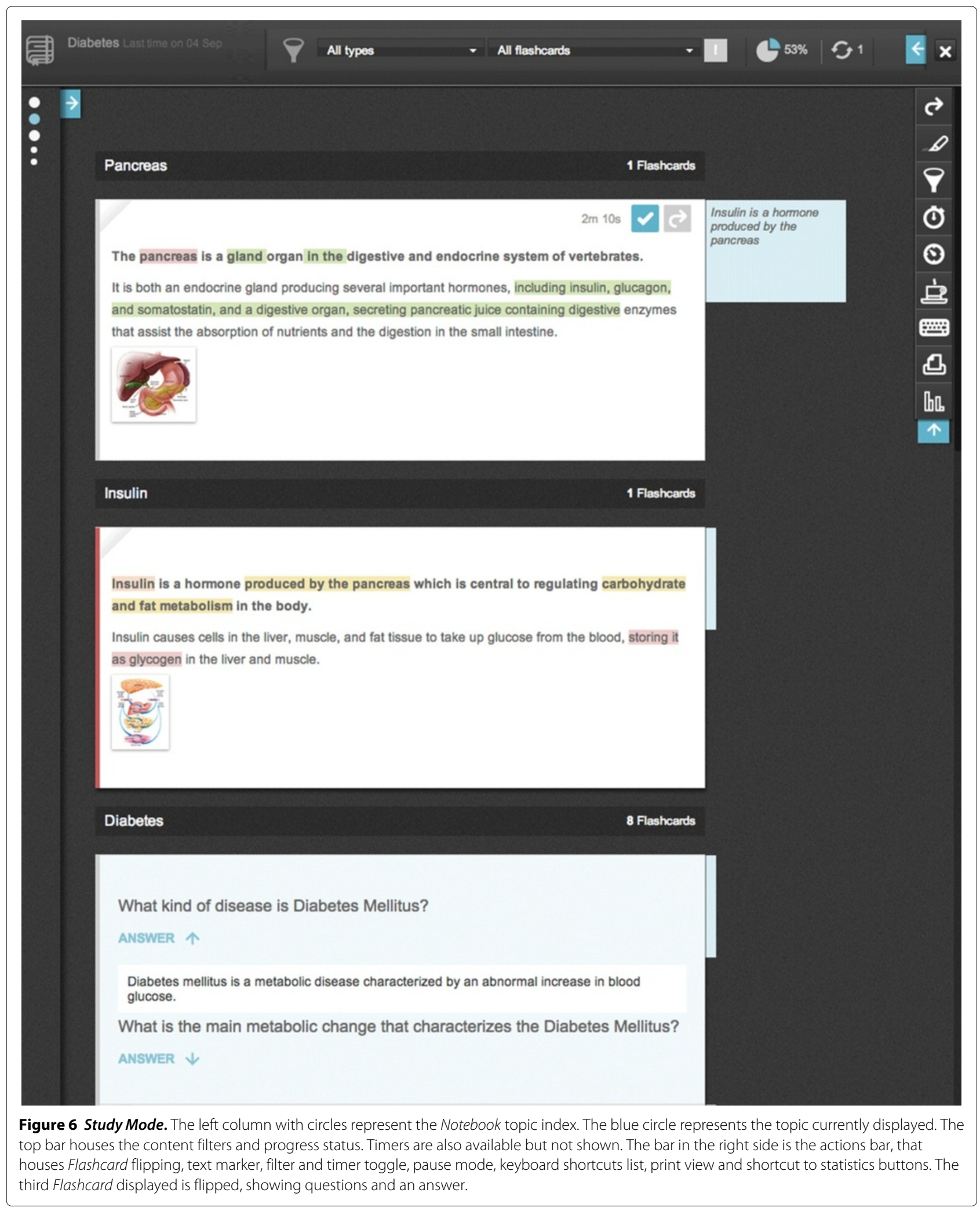




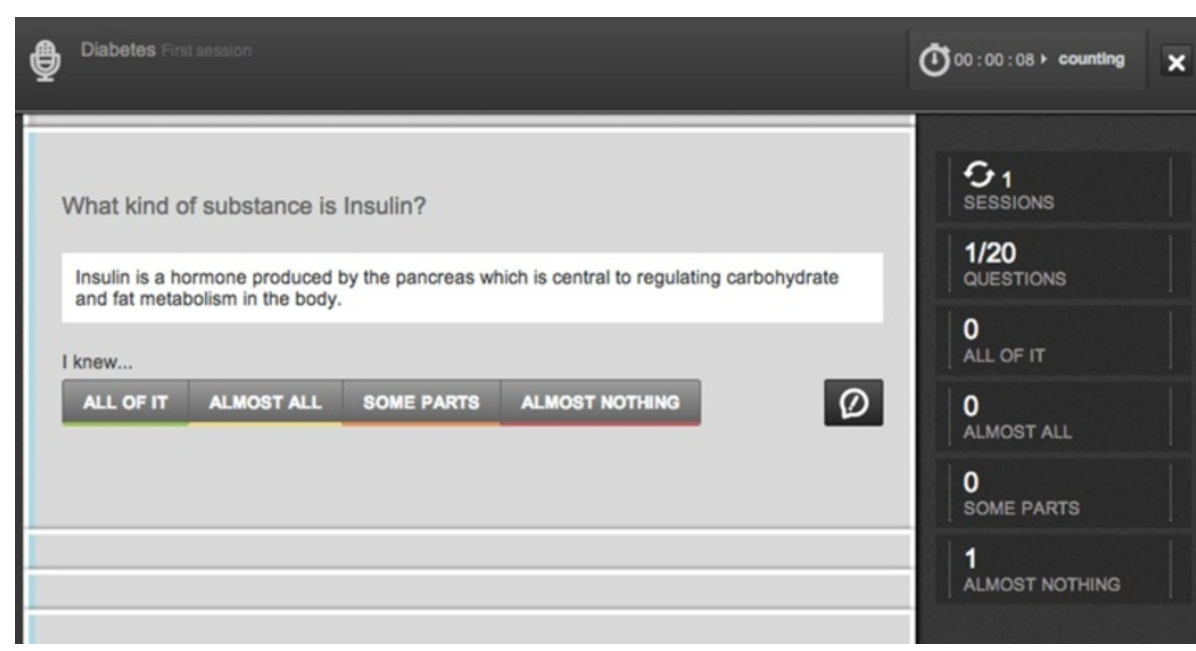

Figure 7 Quiz Mode. A question card is represented along with the answer. Perception of knowledge is graded using the set of four buttons shown. The rightmost button reporting of errors to the Notebook owner. The column on the right tracks student progress.

component involved in learning new redundant materials, hence increasing learning performance [31].

\section{Notebooks}

Notebooks can be accessed through Group pages or through a global Notebook page. Both pages provide search and filter features. (Figure 3) The Notebook Dashboard shows overall information and study statistics regarding personal study performance. Users can analyze Flashcard size and Time spent studying using a sunburst chart (Figure 4). A toggle button resizes each Flashcard representation to match either its character count or

Table 4 System usability and tool usefulness survey

\begin{tabular}{|c|c|c|c|c|}
\hline $\mathbf{n}$ & Item & S1 & S2 & $\mathbf{p}$ \\
\hline 1 & It was easy to study using the computer & $3.21(0.69)$ & $3.38(0.61)$ & 0.04 \\
\hline 2 & The Study Mode was easy to use and understand & $3.68(0.52)$ & $3.81(0.40)$ & 0.06 \\
\hline 3 & $\begin{array}{l}\text { The division of content using topics and } \\
\text { Flashcards was easy to understand }\end{array}$ & $3.64(0.53)$ & $3.68(0.47)$ & 0.60 \\
\hline 4 & $\begin{array}{l}\text { The division of Flashcards into Facts, Details, } \\
\text { Images and Questions was easy to understand }\end{array}$ & $3.60(0.58)$ & $3.77(0.43)$ & 0.04 \\
\hline 5 & $\begin{array}{l}\text { The division of Flashcards into Facts, Details, Images } \\
\text { and Questions helped to understand the key } \\
\text { information to memorize }\end{array}$ & $3.43(0.58)$ & $3.45(0.72)$ & 0.84 \\
\hline 6 & The information on the Flashcards was simple and clear & $3.62(0.49)$ & $3.60(0.54)$ & 0.80 \\
\hline 7 & $\begin{array}{l}\text { The Flashcards were presented in a logical sequence } \\
\text { that facilitates learning }\end{array}$ & $3.34(0.67)$ & $3.43(0.65)$ & 0.29 \\
\hline 8 & $\begin{array}{l}\text { It was easy to find the Flashcards I wish to study using } \\
\text { the Flashcard filters }\end{array}$ & $3.38(0.61)$ & $3.38(0.61)$ & 1.00 \\
\hline 9 & The highlighter and the notes are useful features & $3.66(0.64)$ & $3.72(0.54)$ & 0.41 \\
\hline 10 & The Questions on the Flashcards were easy to understand & $3.34(0.73)$ & $3.45(0.65)$ & 0.37 \\
\hline 11 & The Questions were helpful to help me assess my knowledge about each subject & $3.62(0.61)$ & $3.62(0.53)$ & 1.00 \\
\hline 12 & I could easily find the matching Answer to the Question in the Flashcard Component box & $3.53(0.58)$ & $3.55(0.48)$ & 0.20 \\
\hline 13 & The order in which the Questions were presented did not affect my focus on answering & $3.34(0.90)$ & $3.32(0.69)$ & 0.86 \\
\hline 14 & Without these tools I would not be able to obtain a similar acquired knowledge result & $3.30(0.81)$ & $3.00(0.83)$ & 0.02 \\
\hline
\end{tabular}

S1 and S2 refer to session 1 and session 2. The tasks performed were the same on both sessions. For columns S1 and S2 the values represent mean and standard deviation. Student agreement to each of the items was assessed using a 4-point likert scale: 1 - full disagreement; 2 - partial disagreement; 3 - partial agreement; 4 - full agreement. $p$ values denote differences differences between each session mean. 
Table 5 Willingness to adopt the system as a reference tool

\begin{tabular}{llll}
\hline $\mathbf{n}$ & Item & Mean & SD \\
\hline 15 & I think this system could be used in other basic science subjects & 3.77 & 0.43 \\
\hline 16 & I think this system could be used in clinical science subjects & 3.32 & 0.75 \\
\hline 17 & I see an advantage in using this system as a tool in my daily study & 3.26 & 0.71 \\
\hline 18 & I think this system would allow me to obtain results similar or better than my average results while investing less time studying & 2.96 & 0.83 \\
\hline 19 & I wish this system would encompass the content in the way I am taught at school & 3.51 & 0.62 \\
\hline 20 & I would like to create content to take advantage of it using this system & 3.40 & 0.71 \\
\hline 21 & I would like to collaborate in real time with my colleagues to build useful content fast & 2.94 & 0.63 \\
\hline 22 & I would like to be able to print the notebooks from the system & 3.74 & 0.57 \\
\hline 23 & I would rather use this system instead of my regular notebooks provided all the required content is available & 3.11 & 0.84 \\
\hline 24 & I would rather use this system instead of lecture materials provided all the required content is available & 3.19 & 0.80 \\
\hline 25 & I would rather use this system instead of the recommended bibliography provided all the required content is available & 3.11 & 0.89 \\
\hline 26 & I would recommend this system to my colleagues & 3.66 & 0.52 \\
\hline SD - Standard deviation. Student agreement to each of the items was assessed using a 4-point likert scale: 1 - full disagreement; 2- partial disagreement; - partial \\
agreement; - full agreement.
\end{tabular}

time taken. A bar chart plots Perception of knowledge per topic in two series. One series plots user Perception of knowledge while another plots mean peer Perception of knowledge. A line chart plots Perception of knowledge per quiz session in two series as well. One series plots user Perception of knowledge while another plots mean peer Perception of knowledge (Figure 4). The Notebook editor allows simultaneous creation of Notebooks by searching and selection topics and Flashcards available to be part of a Notebook. New topics and Flashcards can be created as well. A graph of MeSH topic relationships is also displayed and can be used to browse topics (Figure 5).

Flashcards allow content to be created in ways that match specific learning goals and can be reused with little effort to match other learning requirements. Though they are in accordance to the learning objects principles of stand-alone, reusability, interactivity and aggregation [23] (Table 2), the amount of context to build these type of learning objects must be balanced in a way that allows isolated usage in different settings as well as chaining with additional Flashcards in meaningful ways [26]. Enclosing little context in each Flashcard may lead to less articulated Notebooks.

Flashcards are supported by the cognitive load theory. Small chunks of self-enclosed knowledge decrease intrinsic cognitive load. Additionally, since Notebooks are combinations of Flashcards, they can orient learning in a simple-to-complex strategy that further decreases intrinsic cognitive load $[6,9,47]$. Furthermore, this process can be extended by refactoring multiple Notebooks into smaller summary Notebooks containing the most relevant Flashcards that leverage the same cognitive load principles further [47]. Performance data for overlapping
Flashcards can be used to optimize study sessions in a new Notebook setting, which also applies to the principles of learning object re-usability, interactivity and aggregation [47] (Table 2).

The charts allow the student to take action on their study sessions based on Time spent studying and personal and peer Perception of knowledge. Previous works have shown that feedback play a key role in determining learning success [26], hence, insight into performance metrics may help build motivation to learn further.

\section{Study Mode}

The Study Mode allows Notebook study in an adequate digital environment, which minimizes sources of distraction (Figure 6). The dark colors used on the interface contrast with the white Flashcards, creating focus on the area of interest. The center displays the Flashcards stacked as a continuous piece of text. On the side, the index of topics is displayed. It also provides study progress metrics such as percentage of Flashcards studied, number of study sessions, time taken per session, total Time spent studying and Time spent studying on the previous session. Flashcards can be flipped one at a time or altogether to reveal the questions. Flashcards have a button to increment Time spent studying and can be removed from the Quiz Mode assessment by folding the top left corner with a simple click. Additionally, Flashcards have a colored bar on the side that expresses Perception of knowledge. All tool menus are collapsible to prevent distractions. Available tools include filters for Flashcard priority and category, a timer, a stopwatch, notes and text highlighters. Other tools present the keyboard shortcut guide and allow exporting the Notebook in .pdf format. 
In order to increase reading speed, comprehension, and reduce fatigue from screen reading, spaced lines with a mean of 70 characters in length and large window height were used as mentioned in previous studies [48,49]. The ability to hide tools and the keyboard shortcuts further improves focus. Flashcard category and priority filters allow learning sessions to be tailored to personal goals effectively. These features may help reduce extraneous cognitive load related to content navigation tasks and interface visual noise [11,47]. Flipping the Flashcard column provides a tailored "content-and-question" oriented study environment. The ability to resume study sessions from the point that they were last left, further reduces extraneous cognitive load by decreasing distance to the required point of focus $[11,47]$.

\section{Quiz Mode}

The Quiz Mode is the section devoted to self-assessment (Figure 7). It takes the Flashcards of a Notebook, and selects a set of Flashcard questions that are presented one at a time. For each question the user should recall the required knowledge. Afterwards the user reveals the Flashcard section that answers the question and grades Perception of knowledge, the quality of the user recall, using a 4-point likert scale. After grading Perception of knowledge, the system shows another question. The student also has the option of reporting the Flashcard to the Group administrators when inaccuracies are found. After the evaluation step, another card is shown. The system displays student progress and the number of questions rated per grade. When the user finishes the Quiz, statistics about the Time spent studying on each session are presented. The student can also review the Flashcards for the questions with the lowest Perception of knowledge. Questions are chosen so that all flashcard elements are assessed. If more than one question is available for a given content piece, then the system will chose either the hardest question if there are previous ratings, or will pick a question at random. Global Perception of knowledge for each Flashcard is computed by calculating a weighted average of the last three sessions Flashcard Perception of knowledge. The session Perception of knowledge for a Flashcard is calculated by averaging the results for every question answered for the Flashcard in that session.

The Quiz Mode is essential for the system to compute Perception of knowledge. Because each Flashcard may have multiple questions regarding the same content piece, the Quiz Mode is able to use the questions with lowest Perception of knowledge. This provides a means to assess knowledge using questions that are most difficult thereby tailoring memory retention needs. This is also in accordance to the intrinsic cognitive load strategy of low-to-high fidelity tasks because as the student progress, questions representing harder tasks will be preferentially selected [47]. Spaced repetition promotes development strengthening of long-term memory schemata acquired during previous contacts with the Flashcards. This will reduce the amount of elements that will be dealt with using working memory, thus reducing cognitive load and allowing additional focus on the recall process [47]. The way the user grades Perception of knowledge is, however, subject to affective factors. Users may feel inclined to overrate their Perception of knowledge thus decreasing the beneficial effect of the system [50]. Although selfassessment questions are demonstrated to positively affect learning outcomes [16,19,50-53], it remains unknown whether self-reported evaluations correlate with exam grades. This question system has as primary goal to allow self-assessment of simple recall questions. Integrated reasoning questions that require integration of multiple pieces of knowledge are a second and more important step, that the authors intend to develop in the future.

This system implements other features, such as a content repository for FMUP students, the ability to present the Notebooks using full screen Flashcards and, a picture gallery, however these are not presented as their purposes are distinct from the goals of this work.

\section{System usability and adoption surveys}

The student participation rate was $100 \%$ as all of the 48 students randomized to take part in this work accepted to participate. All students completed the two sessions. The score for all items on the survey regarding system usability and tool usefulness (Tables 4 and 5) approached 3.5 (partial to full agreement) in both sessions and overall there were no significant differences between sessions. Both surveys have shown that students generally agreed that the tools provided were useful and simple and were willing to use them as a privileged element for their medical education.

\section{Conclusions}

Overall the application brings a new set of tools that may be helpful to organize knowledge in meaningful ways as well as to manage study sessions, based on personal performance metrics. The system takes into consideration learning object design, instructional design guidelines and principles from cognitive learning theories. Specifically the system allows students to: (1) create personal and reusable learning materials in a collaborative on-line environment (2) self-assess their knowledge through spaced repetition of open ended questions (3) view detailed feedback on their performance and progress (4) easily use the feedback for deliberate practice and to tailor future learning experiences.

Assessment of student performance on content presented through this system and direct comparison of learning outcomes against other learning tools and 
methods are the aims of future work. The development of these features is an important step towards bringing information management tools to support study decisions and improving learning outcomes.

\section{Availability and requirements \\ Project name: ALERT STUDENT}

Project home page: http://www.alert-student.com

Operating systems: Platform independent

Programming languages: HTML, CSS, Javascript, Java, Oracle SQL

Other requirements: Internet explorer 8+, Firefox, Google Chrome, Safari

License: Not opensource

Any restrictions to use by non-academics: No restrictions

\section{Abbreviations}

ACT-R: Adaptive character of thought; CSCL: Computer supported collaborative learning; FMUP: Faculty of Medicine of the University of Porto; HTML: HyperText Markup Language; MeSH: Medical subjects headings; SVG: Standard vector graphics; S1: Study session 1; S2: Study session 2.

\section{Competing interests}

The authors declare that they have no competing interests.

\section{Authors' contributions}

TTG conceived, designed and implemented the system, designed the study and wrote the manuscript. AS conceived and designed the system and wrote the manuscript. MJG oversaw and approved the overall operation for the system development. MS designed the study, performed the statistical analysis and revised the manuscript. MAF oversaw and approved the study design, and revised the manuscript. All authors read and approved the final manuscript.

\section{Acknowledgments}

The project development was funded by Programa Sistema de Incentivos à Investigação e Desenvolvimento Tecnológico (SI I\&DT), projeto no. 6576. The funding source had neither intervention on any phase of the development of the system nor in the writing of this manuscript. We would like to thank the students who took part in the study.

\section{Author details}

${ }^{1}$ Department of Medical Education and Simulation, Faculty of Medicine of the University of Porto, Porto, Portugal. ${ }^{2}$ ALERT Life Sciences Computing, Vila Nova de Gaia, Portugal. ${ }^{3}$ University of California Irvine School of Medicine, Irvine, USA.

Received: 17 November 2013 Accepted: 26 June 2014

Published: 14 July 2014

\section{References}

1. Frenk J, Chen L, Bhutta ZA, Cohen J, Crisp N, Evans T, Fineberg H, Garcia P, Ke Y, Kelley P, Kistnasamy B, Meleis A, Naylor D, Pablos-Mendez A, Reddy S, Scrimshaw S, Sepulveda J, Serwadda D, Zurayk H: Health professionals for a new century: transforming education to strengthen health systems in an interdependent world. Lancet 2010, 376(9756):1923-1958. [http://www.ncbi.nlm.nih.gov/pubmed/ 21112623].

2. Horton R: A new epoch for health professionals' education. Lancet 2010, 376(9756):1875-1877. [http://www.ncbi.nlm.nih.gov/pubmed/ 21112621].

3. Patel VL, Cytryn KN, Shortliffe EH, Safran C: The collaborative health care team: the role of individual and group expertise. Teach Learn Med 2000, 12(3):117-132. [http://www.ncbi.nlm.nih.gov/pubmed/11228898].

4. Schwarz MR, Wojtczak A: Global minimum essential requirements: a road towards competence-oriented medical education. Med Teach 2002, 24(2):125-129. [http://www.ncbi.nlm.nih.gov/pubmed/12098430].
5. Kerfoot BP, Baker H, Jackson TL, Hulbert WC, Federman DD, Oates RD, DeWolf WC: A multi-institutional randomized controlled trial of adjuvant Web-based teaching to medical students. Acad Med 2006, 81(3):224-230. [http://www.ncbi.nlm.nih.gov/pubmed/16501262].

6. Patel VL, Yoskowitz NA, Arocha JF, Shortliffe EH: Cognitive and learning sciences in biomedical and health instructional design: a review with lessons for biomedical informatics education. $J$ Biomed Inform 2009, 42:176-197. [http://dx.doi.org/10.1016/j.jbi.2008.12.002], [http:// www.ncbi.nlm.nih.gov/pubmed/19135173].

7. Sweller J, van Merrienboer JJ, Paas FG: Cognitive architecture and instructional design. Educ Psychol Rev 1998, 10(3):251-296. [http://doc utwente.nl/58655/]

8. Morgulis Y, Kumar RK, Lindeman R, Velan GM: Impact on learning of an e-learning module on leukaemia: a randomised controlled trial. $B M C$ Med Educ 2012, 12:36. [http://www.pubmedcentral.nih.gov/articlerender. fcgi?artid $=3419126 \&$ tool=pmcentrez\&rendertype $=$ abstract] .

9. Dror I, Schmidt $\mathrm{P}, \mathrm{O}^{\prime} \mathrm{connor} \mathrm{L}$ : A cognitive perspective on technology enhanced learning in medical training: great opportunities, pitfalls and challenges. Med Teach 2011, 33(4):291-296. [http://www.ncbi.nlm. nih.gov/pubmed/21456986].

10. van Merriënboer JJG, Sweller J: Cognitive load theory in health professional education: design principles and strategies. Med EduC 2010, 44:85-93. [http://www.ncbi.nlm.nih.gov/pubmed/20078759].

11. Mayer RE: Applying the science of learning to medical education. Med Educ 2010, 44(6):543-549. [http://www.ncbi.n/m.nih.gov/pubmed/ 20604850].

12. Choules AP: The use of elearning in medical education: a review of the current situation. Postgrad Med J 2007, 83(978):212-216. [http:// www.pubmedcentral.nih.gov/articlerender.fcgi?artid $=2600032 \&$ tool $=$ pmcentrez\&rendertype $=$ abstract].

13. Khalil MK, Paas F, Johnson TE, Payer AF: Interactive and dynamic visualizations in teaching and learning of anatomy: a cognitive load perspective. Anat Rec B New Anat 2005, 286:8-14. [http://www.ncbi.nlm. nih.gov/pubmed/16177993].

14. Kerfoot $\mathrm{BP}, \mathrm{Baker} \mathrm{H}$ : An online spaced-education game to teach and assess residents: a multi-institutional prospective trial. J Am Coll Surg 2012, 214(3):367-373. [http://www.ncbi.nlm.nih.gov/pubmed/ 22225647].

15. Shaw T, Long A, Chopra S, Kerfoot BP: Impact on clinical behavior of face-to-face continuing medical education blended with online spaced education: a randomized controlled trial. $J$ Contin Educ Health Prof 2011, 31(2):103-108. [http://www.ncbi.nlm.nih.gov/pubmed/ 21671276].

16. Kerfoot BP, Fu Y, Baker H, Connelly D, Ritchey ML, Genega EM: Online spaced education generates transfer and improves long-term retention of diagnostic skills: a randomized controlled trial. J Am Coll Surg 2010, 211(3):331-337 .e1. [http://www.ncbi.nlm.nih.gov/pubmed/ 20800189].

17. Cook Da, Levinson AJ, Garside S, Dupras DM, Erwin PJ, Montori VM: Instructional design variations in internet-based learning for health professions education: a systematic review and meta-analysis. Acad Med 2010, 85(5):909-922. [http://www.ncbi.nlm.nih.gov/pubmed/ 20520049].

18. Kerfoot BP, DeWolf WC, Masser BA, Church PA, Federman DD: Spaced education improves the retention of clinical knowledge by medical students: a randomised controlled trial. Med Educ 2007, 41:23-31. [http://www.ncbi.nlm.nih.gov/pubmed/17209889].

19. Trial C, Cook DA, Thompson WG, Thomas KG, Thomas MR, Pankratz VS: Impact of self-assessment questions and learning styles in Webbased learning: a randomized, controlled, crossover trial. Acad Med 2006, 81(3):231-238. [http://www.ncbi.nlm.nih.gov/pubmed/16501263]

20. Harden RM, Gessner IH, Gunn M, Issenberg SB, Pringle SD, Stewart A: Creating an e-learning module from learning objects using a commentary or 'personal learning assistant'. Med Teach 2011, 33(4):286-290. [http://www.ncbi.nlm.nih.gov/pubmed/21456985].

21. Clark R, Mayer R: Applying the segmenting and pretraining principles: managing complexity by breaking a lesson into parts. In E-Learning and the Science of Instruction: Proven Guidelines for Consumers and Designers of Multimedia. San Francisco: Jossey-Bass; 2010:207-218. 
22. Masters K, Ellaway R: e-Learning in medical education Guide $\mathbf{3 2}$ Part volume=2, technology, management and design. Med Teach 2008, 30(5):474-489. [http://www.ncbi.nlm.nih.gov/pubmed/18576186]

23. Ruiz JG, Mintzer MJ, Issenberg SB: Learning objects in medical education. Med Teach 2006, 28(7):599-605. [http://www.ncbi.nlm.nih. gov/pubmed/17594550].

24. Kim S, Song SM, Yoon YI: Smart learning services based on smart cloud computing. Sensors 2011, 11(8):7835-7850. [http://www. pubmedcentral.nih.gov/articlerender.fcgi?artid=3231729\&tool= pmcentrez\&rendertype $=$ abstract $]$.

25. Boulos MNK, Maramba I, Wheeler S: Wikis, blogs and podcasts: a new generation of Web-based tools for virtual collaborative clinical practice and education. BMC Med Educ 2006, 6:41. [http://www. pubmedcentral.nih.gov/articlerender.fcgi?artid=1564136\&tool= pmcentrez\&rendertype=abstract].

26. Martinez M: Designing learning objects to personalize learning. $P h D$ thesis, Bloomington IL 2002

27. Beux PL, Fieschi M: Virtual biomedical universities and e-learning. Int Med Inform 2007, 76(5-6):331-335. [http://www.ncbi.nlm.nih.gov/ pubmed/17407747]

28. Ruiz JG, Mintzer MJ, Leipzig RM: The impact of E-learning in medical education. Acad Med 2006, 81(3):207-212. [http://www.ncbi.nlm.nih. gov/pubmed/16501260].

29. Patel VL, Yoskowitz NA, Arocha JF: Towards effective evaluation and reform in medical education: a cognitive and learning sciences perspective. Adv Health Sci Educ Theory Pract 2009, 14(5):791-812.

30. Harden $\mathrm{R}$ : The virtual learning environment in medical education past, present and future. In Medical Education: The State of the Art. Edited by Salerno-Kennedy R, O'Flynn S. Hauppauge, NY: Nova Science Publishers Inc.; 2010:1-10.

31. McKendree J: Understanding Medical Education: Oxford: Wiley-Blackwell; 2010. [http://doi.wiley.com/10.1002/9781444320282]

32. Bahner DP, Adkins E, Patel N, Donley C, Nagel R, Kman NE: How we use social media to supplement a novel curriculum in medical education. Med Teach 2012. [http://informahealthcare.com/doi/abs/10. 3109/0142159X.2012.668245]

33. Eysenbach G: Medicine 2.0: social networking, collaboration, participation, apomediation, and openness. J Med Internet Res 2008, 10(3):e22. [http://www.pubmedcentral.nih.gov/articlerender.fcgi?artid= 2626430\&tool=pmcentrez\&rendertype=abstract].

34. Kind T, Genrich G, Sodhi A, Chretien KC: Social media policies at US medical schools. Med Educ Online 2010, 15: [http://www. pubmedcentral.nih.gov/articlerender.fcgi?artid=2941429\&tool= pmcentrez\&rendertype=abstract].

35. Chretien KC, Greysen SR, Chretien JP, Kind T: Online posting of unprofessional content by medical students. JAMA 2009, 302(12):1309-1315. [http://www.ncbi.nlm.nih.gov/pubmed/19773566].

36. McGrath RG: Exploratory learning, innovative capacity and managerial oversight. Acad Manag J 2001, 44:118-131. [http://www. jstor.org/stable/3069340].

37. Koops W, Van der Vleuten, C, De Leng B, Oei SG, Snoeckx L: Computer-supported collaborative learning in the medical workplaceStudents' experiences on formative peer feedback of a critical appraisal of a topic paper. Med Teach 2011, 33(6):e318-e323. [http://www.ncbi.nlm.nih.gov/pubmed/21609168]

38. Chan $\mathrm{CH}$, Robbins LI: E-Learning systems: promises and pitfalls. Acad Psychiatry 2006, 30(6):491-497. [http://www.ncbi.nlm.nih.gov/pubmed/ 17139020].

39. Curran VR, Fleet $L$ : A review of evaluation outcomes of web-based continuing medical education. Med Educ 2005, 39(6):561-567. [http:// www.ncbi.n/m.nih.gov/pubmed/15910431].

40. Paton C, Bamidis PD, Eysenbach G, Hansen M, Cabrer M: Experience in the use of social media in medical and health education. contribution of the IMIA social media working group. Yearb Med Inform 2011, 6:21-29. [http://www.ncbi.nlm.nih.gov/pubmed/21938320], [http://repository.usfca.edu/nursing_fac/6].

41. Hannig A, Kuth N, Özman M, Jonas S, Spreckelsen C: eMedOffice: a web-based collaborative serious game for teaching optimal design of a medical practice. BMC Med Educ 2012, 12:104. [http://www. pubmedcentral.nih.gov/articlerender.fcgi?artid=3506465\&tool= pmcentrez\&rendertype $=$ abstract $]$.
42. Triola MM, Holloway WJ: Enhanced virtual microscopy for collaborative education. BMC Med Educ 2011, 11:4. [http://www. pubmedcentral.nih.gov/articlerender.fcgi?artid=3037351\&tool= pmcentrez\&rendertype $=$ abstract].

43. Al-Jasmi F, Moldovan L, Clarke JTR: Hunter disease eClinicinteractive, computer-assisted, problem-based approach to independent learning about a rare genetic disease. BMC Med Educ 2010, 10:72 [http://www.pubmedcentral.nih.gov/articlerender.fcgi?artid= 2987933\&tool=pmcentrez\&rendertype=abstract].

44. Nilsson M, Bolinder G, Held C, Johansson BI, Fors U, Ostergren J: Evaluation of a web-based ECG-interpretation programme for undergraduate medical students. BMC Med Educ 2008, 8:25. [http:// www.pubmedcentral.nih.gov/articlerender.fcgi?artid=2394519\&tool= pmcentrez\&rendertype=abstract].

45. John NW: The impact of Web3D technologies on medical education and training. Comput Educ 2007, 49:19-31. [http://linkinghub.elsevier. com/retrieve/pii/S0360131505000825]

46. Mayer RE: Applying the science of learning to medical education. Med Educ 2010, 44(6):543-549. [http://www.ncbi.nlm.nih.gov/pubmed/ 20604850].

47. van Merriënboer JJG, Sweller J, Merrie JJGV: Cognitive load theory in health professional education: design principles and strategies. Med Educ 2010, 44:85-93. [http://www.ncbi.nlm.nih.gov/pubmed/20078759].

48. Dyson M: Exploring the effect of layout on reading from screen Electronic Publishing, Artistic Imaging, and Digital 1998. [http://www. springerlink.com/index/K44N3J9L22777K1X.pdf].

49. Dillon $A$, MCKnight $C$ : Reading from paper versus reading from screen. Comput J 1988. [http://comjnl.oxfordjournals.org/content/31/5/ 457.short]

50. Sitzmann T, Ely K, Brown KG, Bauer KN: Self-assessment of knowledge: a cognitive learning or affective measure?. Acad Manag Learn EduC 2010, 9(2):169-191.

51. Kerfoot BP, Shaffer K, McMahon GT, Baker H, Kirdar J, Kanter S, Corbett EC, Berkow R, Krupat E, Armstrong EG: Online "spaced education progress-testing" of students to confront two upcoming challenges to medical schools. Acad Med 2011, 86(3):300-306. [http://www.ncbi. nlm.nih.gov/pubmed/21248600]

52. Kerfoot $B P$, Brotschi $E$ : Online spaced education to teach urology to medical students: a multi-institutional randomized trial. Am J Surg 2009, 197:89-95. [http://www.ncbi.nlm.nih.gov/pubmed/18614145]

53. Kerfoot BP: Interactive spaced education versus web based modules for teaching urology to medical students: a randomized controlled trial. J Urol 2008, 179(6):2351-2356. discussion 2356-2357 [http://www. ncbi.nlm.nih.gov/pubmed/18423715]

doi:10.1186/1472-6920-14-143

Cite this article as: Taveira-Gomes et al: A novel collaborative e-learning platform for medical students - ALERT STUDENT. BMC Medical Education 2014 14:143.
Submit your next manuscript to BioMed Central and take full advantage of:

- Convenient online submission

- Thorough peer review

- No space constraints or color figure charges

- Immediate publication on acceptance

- Inclusion in PubMed, CAS, Scopus and Google Scholar

- Research which is freely available for redistribution

Submit your manuscript at www.biomedcentral com/submit
C Biomed Central 